\title{
Uso do LabView para o Controle de um Veículo
}

\section{Labview Application For A Vehicle Control}

\author{
Ruberlei Gaino ${ }^{1}$; Reinaldo Gonçalves Nogueira²; \\ Wilson Eduardo Francischi ${ }^{3}$, Douglas Paladine Vieira ${ }^{3}$
}

\begin{abstract}
Resumo
Este artigo aborda a construção de um veículo acionado por motores elétricos inspirado nos artigos (MAZO, 1995; FONSECA SOBRINHO, 2000) e que seja automatizado, ou seja, possa locomover-se dentro de qualquer ambiente sem que seja necessária a intervenção humana. $\mathrm{O}$ controle foi feito utilizando o software Labview, com aquisição de dados e geração de sinais de controle. O veículo possui um sistema de sensores infravermelhos que indicam a existência de um obstáculo à frente do veículo, informando que o mesmo deve parar e contorná-lo. O programa implementado é o responsável pelo comando dos motores que fazem o protótipo andar e contornar os objetos.

Poder ter o controle de um veículo à distância é importante em situações nas quais seria perigoso para um ser humano. A principal vantagem deste sistema é que pode-se ter total maleabilidade para que se façam alterações no software de comando, sem que seja necessário tocar a parte física do protótipo. Pode-se concluir deste trabalho que o sistema é eficiente, sendo capaz de se movimentar em uma sala com objetos sem tocá-los.
\end{abstract}

Palavras Chave: Labview, Veículo Autônomo, Motores Elétricos.

\begin{abstract}
This article deals with the construction of a vehicle driven by electric motors and that is automated, that is, that can move anywhere without human intervention. The control was done using the software Labview, with data acquisition and generation of control signs. The vehicle has an infrared sensors system that indicates the existence of an obstacle ahead the vehicle, informing it that it should stop and bypass the obstacle. The program is the responsible for the engine control, making it possible for the prototype to run and bypass the objects that block its way. The possibility of remote-controlling a vehicle is very important is risky situations for human beings, for example in radioactive places. The main advantage of this system is the total flexibility for making alterations in the control software, without being necessary to touch the physical part of the prototype. The conclusion of this work is that the system is efficient and able to move in a room with objects without touching them.
\end{abstract}

Key Words: Labview, Autonomous Vehicle, Electrical Motors.

\section{Introduçao}

A necessidade de ter o controle de máquinas, para que estas executem serviços cada vez mais comple- xos e perigosos para o homem, faz com que, atualmente, a robótica seja um dos temas mais pesquisados.

\footnotetext{
${ }^{1}$ Professor do Departamento de Engenharia Elétrica da Universidade Estadual de Londrina. E-mail: ruberlei@uel.br

${ }^{2}$ Professor da Escola de Engenharia Elétrica e de Computação da Universidade Federal de Goiás. E-mail: reinaldo@eee.ufg.br

${ }^{3}$ Alunos de Iniciação Científica do curso de Engenharia Elétrica da Universidade Estadual de Londrina.
} 
Este artigo discute a implementação de um veículo autônomo, dotado de sensores, capaz de se locomover por todo um ambiente não previamente conhecido.

Este trabalho é dividido em duas estapas:

- Construção do veículo a ser controlado e do sistema de sensores.

- Implementação do programa de controle através de um software de instrumentação virtual (Labview).

As duas estapas citadas acima foram desenvolvidas simultaneamente, pois uma está diretamente ligada à outra. Para a implementação do programa, foi utilizado o software Labview versão 6i. Na construção do protótipo, foram utilizados dois motores elétricos, sendo um de passo e outro de corrente contínua.

Para que o veículo possa detectar barreiras que obstruem sua passagem, foi desenvolvido um sistema de três sensores infravermelhos localizados à frente do protótipo. Assim, quando um obstáculo é encontrado, o móvel desvia do mesmo sem tocá-lo.

O programa implementado é capaz de receber os sinais dos sensores, processá-los de maneira a indicar os obstáculos e enviar os comandos corretos para os motores, o que permite ao móvel locomoverse de forma autônoma.

Os motores, um de passo, e um de corrente contínua, são os responsáveis pelo direcionamento e deslocamento do veículo respectivamente. Isso possibilita o controle total do espaço percorrido pelo protótipo.

Este programa deve ser capaz de receber um sinal enviado por um sensor, fazer o tratamento deste sinal, indicando se há ou não um obstáculo à frente do veículo e enviar os comandos para os motores elétricos.
A interface entre o programa e o veículo é feita por meio de uma placa de geração e aquisição de sinais, produzida pela National Instuments e específica para o software em questão. A troca de sinais entre o mini-robô e a placa de interface é feita por intermédio de fios.

A figura 1, abaixo, ilustra o modelo implementado de forma a mostrar o conjunto completo, veículo, placa de interface e microcomputador.

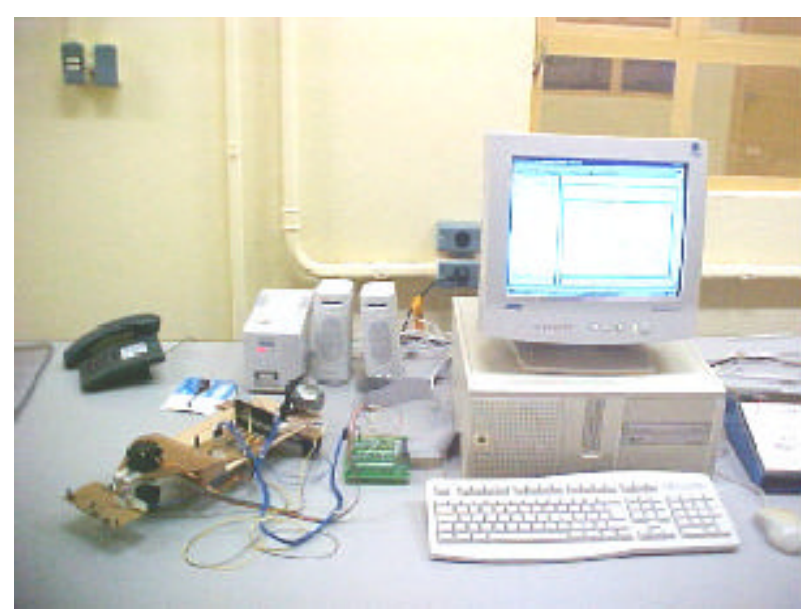

Figura 1. Foto do veículo construído, a placa de interface e o microcomputador utilizado para o projeto.

\section{Labview $x$ Microcontrolador}

$O$ fato de ter sido utilizado um software de instumentação virtual (Labview), ao invéz de um microcontrolador, para ser o responsável pelo controle do veículo, é porque se pretende continuar trabalhando neste projeto, dando-se novas atribuições ao protótipo, como o controle manual do deslocamento do veículo e de sua velocidade. Ocorre que implementar essas novas atribuições por meio do uso de um microcontrolador torna-se complexo, já que se necessita de um bom domínio em linguagem de programação assembly. Além disso, tem-se a possibilidade de acoplar uma câmera de vídeo a bordo do veículo, para que se possa controlá-lo à distância, por meio da internet. 


\section{Desenvolvimento}

\section{Materiais utilizados}

Foram utilizados um microcomputador Pentium $450 \mathrm{MHz}$ (com o software Labview versão $6 \mathrm{i}$ instalado); sua placa para interface entre o computador e o veículo (pela qual chegarão e sairão os sinais); um motor de corrente contínua; um motor de passo, quatro circuitos integrados, sendo um 7486 (quatro portas ou-exclusvo), um 7474 (dois flip-flops tipo D), um ULN 2003 (amplificador de corrente), e um sn7406 (portas inversoras); quatro transístores TIP (dois 145 e dois 142); fotodiodos; fototransístores; e também resistores de $68 \mathrm{~W}$ e $1 \mathrm{MW}$.

\section{Sistema de Sensores}

O sensor (PATON, 1999) utilizado baseia-se no princípio da reflexão da luz. Utiliza-se um fotodiodo que emite luz infravermelha constantemente, e, ao lado do fotodiodo, um fototransistor, cuja base é polarizada quando luz infravermelha a atinge. O nível de saturação da base é proporcional à quantidade de luz recebida, ou seja, se a quantidade de luz que incide diretamente na base não for suficiente para que tenhamos o transistor trabalhando na região ativa ou de saturação, ele vai estar em corte. Assim, não vai haver passagem de corrente elétrica entre o coletor e o emissor, logo a tensão de emissor vai ser zero.

Construiu-se uma placa com três pares fotodiodofototransistor distribuídos uniformemente à frente do veículo. Então, quando houver um objeto que reflita luz a uma distância razoável - na qual a quantidade de luz refletida seja capaz de polarizar a base do fototransistor - haverá uma passagem de corrente pelo resistor do emissor e a tensão em cima do mesmo será enviada para o Labview por meio da placa de interface.

Os valores captados pelos três sensores precisam ser comparados a algum valor de referência para poder determinar se há ou não um obstáculo. Para resolver este problema utilizou-se mais um fototransistor localizado aproximadamente cinco centímetros atrás dos outros. Este fototransistor tem sua base polarizada somente pela existente no meio onde se encontra, fornecendo, assim, uma referência para fins de comparação no programa. Isso é importante, uma vez que o móvel pode mudar de ambiente ou, de uma hora para outra, aumentar a quantidade de luz infravermelha no local onde se encontra. Enquanto não houver objetos que reflitam a luz emitida pelo LED, a diferença de tensão entre os emissores dos três fototransistores de sensoriamento deve ser aproximadamente igual a zero. E quando houver uma diferença de tensão de $0,4 \mathrm{~V}$ entre as tensões de qualquer um dos três fototransístores de sensoriamento e o de referência significa que há alguma barreira atrapalhando a passagem do veículo. A figura 2 ilustra o funcionamento do sistema de sensores.

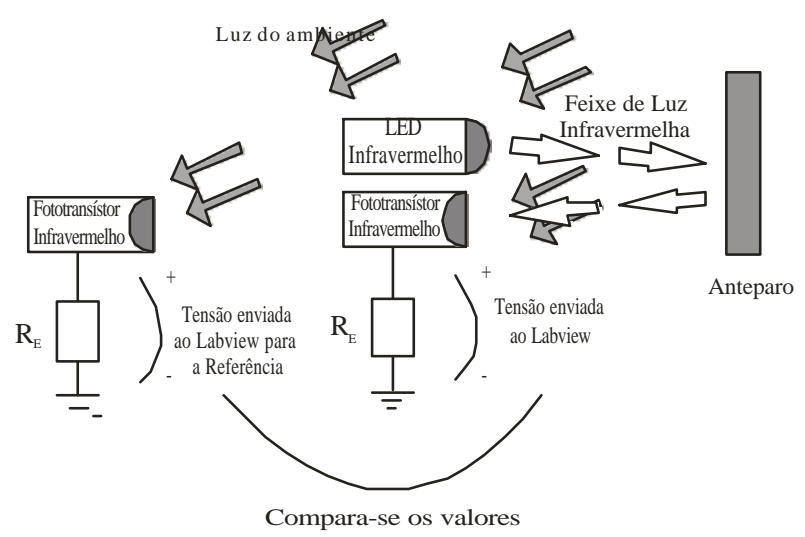

Figura 2. Ilustração do funcionamento do sensor implementado com o fototransistor de referência.

O valor de $0,4 \mathrm{~V}$ foi encontrado de forma empírica. Realizaram-se diversos testes e determinou-se uma variação média de quatro décimos de volt no caso de um obstáculo estiver a aproximadamente 11 (onze) centímetros de distância do sensor. Essa distância é relativa, pois é dependente da cor do objeto que reflete a luz. Existem anteparos que refletem mais ou menos luz, o que causa diferença na distância 
detectada entre o objeto e o veículo. Os testes para verificar a distância e o valor de tensão foram realizados com um pedaço de papelão.

O circuito contendo os três sensores mais o sensor de referência é mostrado na figura 3.

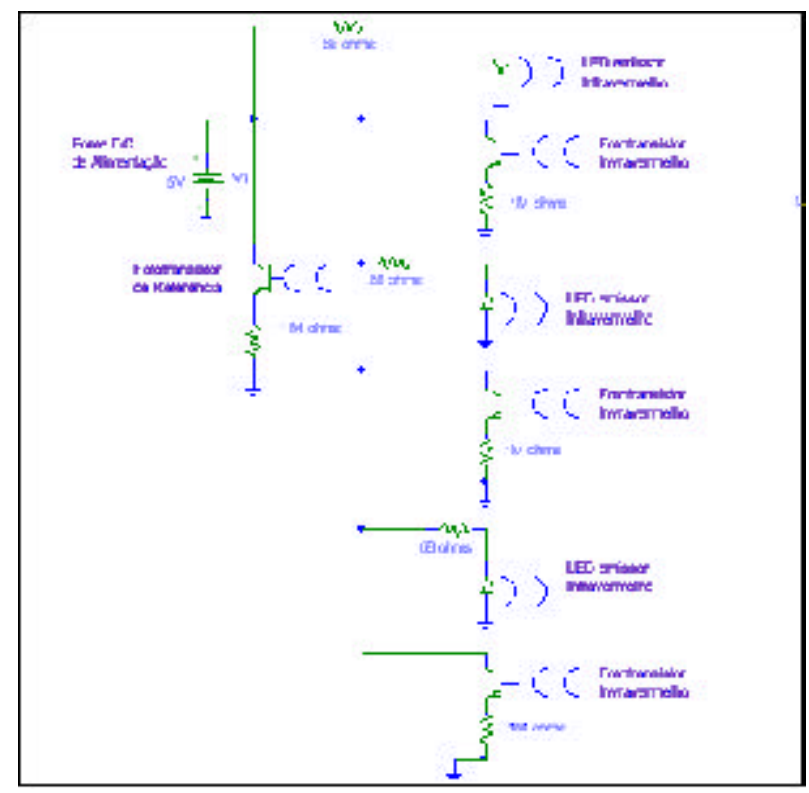

Figura 3. Circuito dos sensores utilizados no projeto.

A resistência colocada em série com o LED destina-se ao limitar a corrente que o atravessa e, assim, evitar que se danifique o diodo emissor de luz. A resistência que está em série com o emissor do fototransistor tem a finalidade de controlar a corrente e causar uma diferença de potencial entre o terra e o emissor, valor este enviado para o programa para fins de comparação.

\section{Programa para Controle}

O programa deve trabalhar sempre com a hierarquia das operações, na qual cada operação depende primeiramente do resultado das comparações dos sinais provenientes dos sensores.

Foram utilizados três sensores, e isso possibilitou a construção de um programa capaz de "decidir" em que sentido o veículo deveria girar para desviar do anteparo que obstrui sua passagem. É possível então realizar os seguintes cálculos comparativos:

$$
\begin{aligned}
& V_{E 1}-0,4^{3} V_{\text {EREF }} \\
& V_{E 2}-0,4{ }^{3} V_{\text {EREF }} \\
& V_{E 3}-0,4^{3} V_{\text {EREF }}
\end{aligned}
$$

onde, $\mathrm{V}_{\mathrm{E} 1}, \mathrm{~V}_{\mathrm{E} 2} \mathrm{e} \mathrm{V}_{\mathrm{E} 3}$ são os valores de tensão no emissor dos fototransistores. Definiu-se que $V_{E 1}$ é o fototransistor mais à esquerda, $\mathrm{V}_{\mathrm{E} 2} \mathrm{o}$ central, $\mathrm{e}_{\mathrm{E} 3} \mathrm{O}$ mais à direita.

A possibilidade de qualquer uma das três operações ser verdadeira, significa que existe um objeto à frente do veículo. O programa é capaz de perceber em que lado o objeto que obstrui sua passagem se encontra e desviar o móvel para o lado oposto.

Para o programa executar esta tarefa, estipulamse pesos para cada uma das três operações realizadas (4 para $\mathrm{V}_{\mathrm{E} 1}$, 2 para $\mathrm{V}_{\mathrm{E} 2}$ e 1 para $\mathrm{V}_{\mathrm{E} 3}$ ) e transformam-se as respostas em valores booleanos, ou seja, 0 (zero) para quando a operação for falsa e 1 (um) quando for verdadeira. Multiplicam-se então as respostas por seus respectivos pesos e soma-se todos os resultados. Compara-se então o valor final com cada possibilidade, ou seja, a soma pode variar de 0 (zero) até 7 (sete). De acordo com o valor obtido, o programa executa uma linha de tarefas e orienta a melhor direção para o veículo seguir.

Para cada possibilidade existe uma estrutura seqüencial dentro de sua estrutura condicional. Os valores possíveis para a soma resultam nas seguintes tarefas executadas (valor - tarefa):

0- Nenhum obstáculo detectado: o protótipo continua seu caminho para frente, buscando novos obstáculos.

1- Obstáculo à direita: sem parar seu movimento, o veículo realiza uma curva para a esquerda, e segue para frente. 
2- Obstáculo ao centro do percurso: o protótipo pára, vai para trás desviando para a direita, realinha seu eixo e o veículo volta a ir para frente, procurando novos obstáculos.

3- Obstáculo ao centro e à direita: o protótipo para e anda em marcha ré, enquanto desvia para a esquerda, realinha seu eixo e volta a seu curso normal.

4- Obstáculo à esquerda: o veículo desvia para a direita, sem parar de se locomover.

5- Obstáculo presente à direita e à esquerda: o carrinho pára, vai para trás enquanto desvia para a direita, realinha seu eixo e, então, volta a seu curso normal.

6- Obstáculo ao centro e à esquerda: o veículo pára de se locomover e tem seu curso desviado para a direita enquanto se move em marcha à ré, retornando à sua trajetória original ao fim da manobra.

7- Obstáculo à frente do protótipo: o carrinho para seu movimento, vira para a direita enquanto está indo para trás, e após isso, volta a ir para frente procurando novos obstáculos.

O protótipo desvia sempre para a direita quando um obstáculo é detectado somente pelo sensor central, isto foi adotado sem nenhuma razão maior.

A figura 04, abaixo, exibe a janela do programa implementado. Do lado esquerdo, o laço while que compara os valores provenientes dos sensores. E do lado direito, as estruturas seqüenciais que são chamadas quando um obstáculo é encontrado.

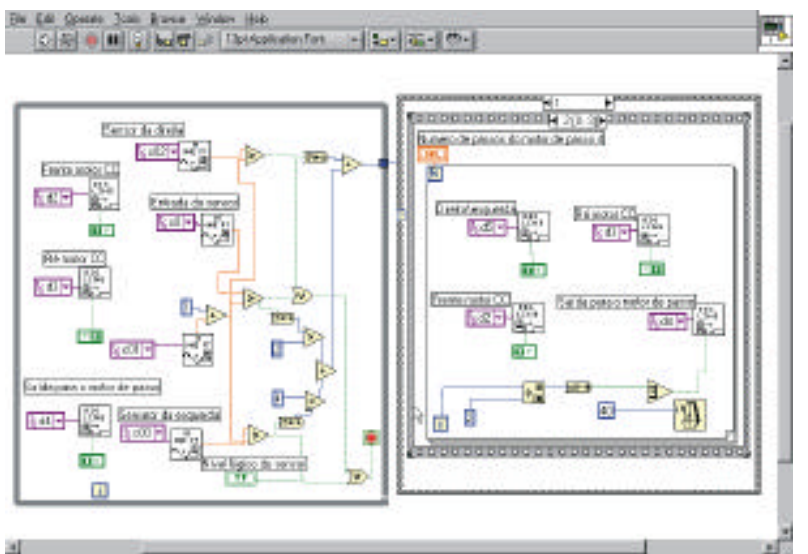

Figura 4. Janela do programa implementado no Labview.

\section{Acionamento do motor de passo}

O motor de passo é um transdutor que converte energia elétrica em movimentos controlados por meio de pulsos, possibilitando um deslocamento por passo, no qual um passo é o menor deslocamento angular. Escolheu-se este tipo de motor para fazer o direcionamento esquerda/direita do veículo, já que com isso se pode programar o número de passos que o motor executará.

O motor de passo gira quando suas bobinas são energizadas de forma seqüencial e repetida. Mas pode-se energizar suas bobinas duas a duas seqüencialmente, desde que apresentem defasagem de $90^{\circ}$, dessa forma, em uma seqüência, possibilitase o giro do motor de modo contínuo. Esta configuração permite um torque maior do que quando se energizam as bobinas individualmente. Isso ocorre porque o rotor é magneticamente ativo e a energização das bobinas cria um campo magnético intenso que atua no sentido de se alinhar com os pólos do rotor, então possuindo duas bobinas energizadas, o campo magnético vai ser maior.

Construiu-se um circuito que, além de ter a característica citada acima (possuir maior torque) também permite que se utilizem somente dois fios, que conduzem sinais digitais, para o acionamento e controle do motor. Um dos fios é responsável pelo sentido de giro do motor, ou seja, se for nível lógico 1 (um) gira em sentido horário e se for 0 (zero) gira em sentido anti-horário. $\mathrm{O}$ outro fio aciona o motor por meio de um trem de pulsos e desliga o mesmo quando mantido em nível lógico baixo.

O circuito implementado é constituído de dois flip-flops (CI 7474) e duas portas lógicas ou-exclusivo (CI 7486). Um amplificador de corrente (CI 2003) faz-se necessário. A potência do motor utilizado é de aproximadamente $2 \mathrm{~W}$.

O circuito completo é mostrado na figura 05 . 


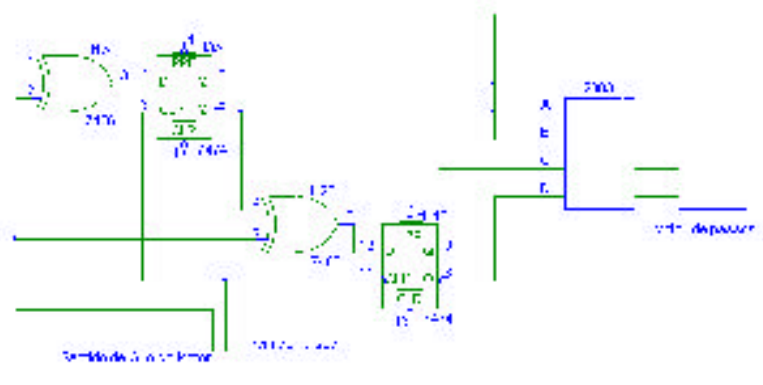

Figura 5. Circuito implementado para acionar o motor de passo.

\section{Acionamento do Motor de Corrente Contínua}

O controle do motor é feito por meio de dois sinais digitais que deixam a placa geradora e receptora do labview. Estes sinais possibilitam quatro diferentes combinações, 0-0, 0-1, 1-0 e 1-1. Esses estados é que determinam o que o motor deve fazer, mas antes, eles passam por um tratamento.

O tratamento do sinal é feito para que se possa inverter o sentido de giro do motor e também amplificar a corrente que é enviada pelo Labview. O circuito possui quatro transistores TIP (darlington), sendo dois 142 (npn) e dois complementares 145 (pnp) ligados em ponte H. Essa implementação permite que se inverta o sentido de giro do motor de acordo com as polarizações na base de cada transistor.

O circuito possui também um circuito integrado 7406 (inversor) que tem a função de inverter alguns valores para que estes polarizem ou não cada um dos transistores. Além disso, a corrente proveniente do labview é muito baixa e não pode saturar a base do transistor sem antes ser amplificada. O CI 7406 também funciona amplificando a corrente. A potência do motor utilizado é de $5 \mathrm{~W}$.

Os resistores de potência colocados são para proteção, e os outros são para definir a corrente na base dos transistores.

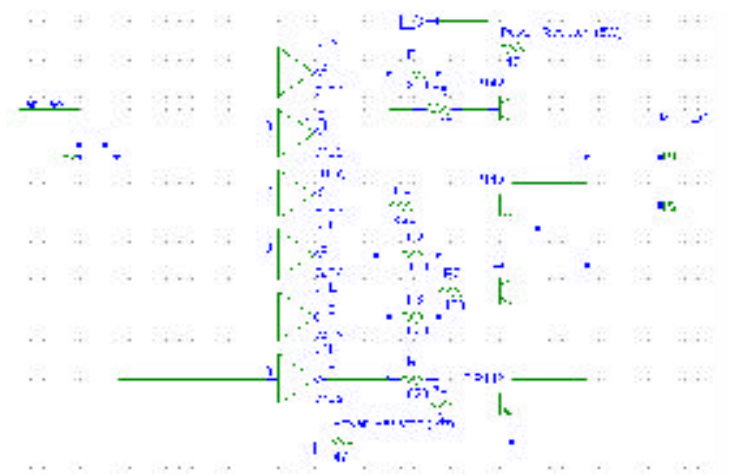

Figura 6. Circuito para o acionamento do motor cc.

Analisando o circuito para o acionamento do motor cc pode-se definir uma tabela de correspondência entre o sinal enviado pelo labview e o estado do motor.

Tabela 1. Relação entre os sinais provenientes da placa de interface e o estado em que o motor vai se encontrar.

\begin{tabular}{cc|cc} 
S1 & S2 & Estado do Motor & Descrição \\
\hline 0 & 0 & Estado proibido & Curto na fonte, salvo pelos resistores de potência \\
0 & 1 & Sentido Horário & Terminal p1 com maior potencial que o terminal \\
1 & 0 & $\begin{array}{c}\text { Sentido anti- } \\
\text { horário } \\
\text { Motor parado }\end{array}$ & Situação inversa a anterior \\
1 & 1 & $\mathrm{p} 1 \mathrm{e} \mathrm{p} 2$ no mesmo potencial
\end{tabular}

\section{Resultados}

Os resultados obtidos foram satisfatórios, e estão de acordo com o proposto inicialmente. $\mathrm{O}$ sistema de sensores mostrou-se eficiente nas diversas situações e condições de iluminação às quais foi submetido. $\mathrm{O}$ acionamento dos motores atendeu ao requisitado pelo programa e o programa implementado está funcionando perfeitamente.

O veículo montado apresentou sucesso total de operação, sendo capaz de encontrar os obstáculos e desviar dos mesmos.

O circuito é apresentado na figura 06. 


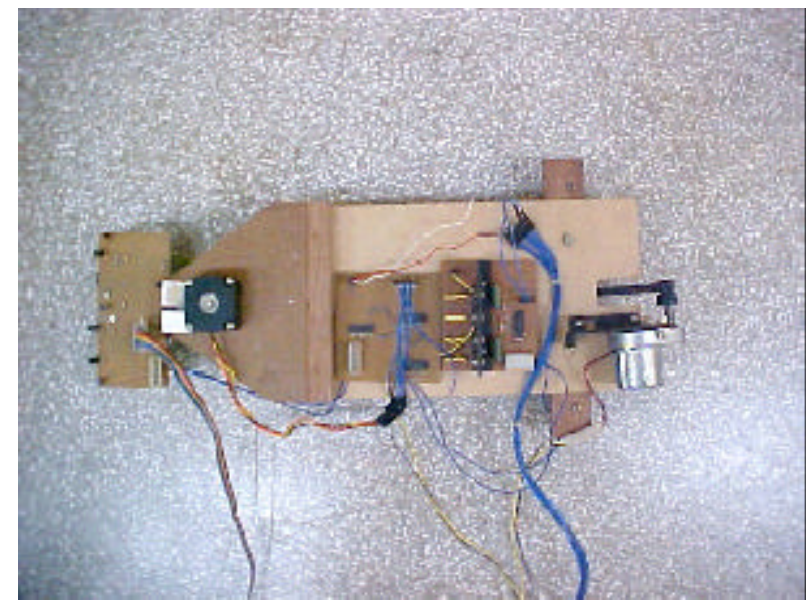

Figura 7. Veículo construído.

\section{Conclusão}

O software utilizado, Labview (NATIONAL INSTRUMENTS CORPORATION, 2000a, 2000b, 2000c), é muito útil e versátil, permitindo inúmeras aplicações em controle. Sua programação é ralativamente simples, uma vez que se tenha uma boa noção de suas funções. A opção pelos microntroladores, dsp's e fpga's é viável, porém foge aos objetivos deste projeto. Além disso mencionamse em publicações da área veículos ligados a microcomputadores que exercem trabalhos de reparos em dutos de óleo, porque dentro de uma tubulação podem ocorrer vários problemas, como perda do sinal e descontrole total do veículo. Por isso, com cabo de alimentação, seu funcionamento fica mais confiável.

O circuito do sensor é muito simples de ser implementado, já que a parte lógica de operação dele foi toda programada no software Labview e não em hardware. A opção de se ter um sensor somente para captar a quantidade de luz existente no meio foi muito útil e permite a utilização do veículo em qualquer ambiente, com diferentes quantidades de iluminação. Sem esta referência seria necessário um outro programa que fosse capaz de comparar os sinais e perceber o aumento da quantidade de luz incidente, tal programa seria mais complexo e menos eficiente, pois não preveria o aumento da luz do ambiente como um todo.

O Circuito desenvolvido para o motor de passo apresenta algumas vantagens sobre o acionamento direto que utilizaria quatro fios para a ligação. A principal é a redução no número de ligações entre os sistemas, que cai de quatro para duas, assim permite que se utilize as portas que não foram utilizadas em outras aplicações.

\section{Referências}

FONSECA SOBRINHO, A. S. et al. Cadeira de roda controlada por sopros e sucções. Semina: Ci. Exatas/Tecnol. Londrina, v.21, n.4 p.3-7, dez. 2000.

MAZO, M. et al. Electronic control of a wheel chair guided by voice commands. Control Enginnering Practice, v.3, n.5, p.665-674, 1995.

NATIONAL INSTRUMENTS CORPORATION. Get Starterd with LabVIEW. Austin, 2000a. LabVIEW User's Manual. Austin, $2000 \mathrm{~b}$. LabVIEW Measurements Manual. Austin, 2000c.

PATON, B. E. Sensors, transducers \& LabVIEW. New Jersey: Prentice-Hall, Upper Saddle River, 1999. 